\title{
A Fatal Case of Pyrexia of Unknown Origin: Hemophagocytic Lymphohistiocytosis?
}

\author{
${ }^{1}$ Palak Bhuta, ${ }^{2}$ Aakash Patel, ${ }^{3}$ Luv Yadav, ${ }^{4}$ Utsav Patel, ${ }^{5}$ Virendra Kosamia, ${ }^{6}$ Arti Muley
}

\section{ABSTRACT}

Aim: To highlight the need of high suspicion of hemophagocytic lymphohistiocytosis $(\mathrm{HLH})$ in pyrexia of unknown origin (PUO) and also the need of specific guidelines for the management of the disease.

Background:The $\mathrm{HLH}$ is a rare disease of overactive histiocytes and lymphocytes. Although seen in all age groups, it is less common in adults as compared with infants. It usually presents with fever, hepatosplenomegaly, pancytopenia, lymphadenopathy, and rash. Cutaneous involvement is seen in as many as $65 \%$ of patients.

Case report: A 25-year-old male presented with high-grade fever and cough since 4 weeks. Examination at presentation revealed only hepatosplenomegaly. During the course of the disease, he developed pancytopenia, but there was no lymphadenopathy or neurological or cutaneous manifestations. The patient was thoroughly investigated, but it remained inconclusive. He did not respond to any antibiotics, antimalarials, or antituberculars. There was an initial response to steroids, but it did not sustain. Bone marrow remained normal throughout the course of illness. Based on other features, we made a diagnosis of $\mathrm{HLH}$, but the patient's condition worsened rapidly and proved to be fatal despite all treatment.

Conclusion and clinical significance: The HLH must be suspected in a case of PUO especially in presence of pancytopenia and hepatosplenomegaly. It is important to look for other features like hyperferritinemia and hypertriglyceridemia to reach an early diagnosis as bone marrow features may present very late during the course of illness. Early diagnosis is all the more important in view of rapidly progressive fatal course of the disease.

Keywords: Hemophagocytic lymphohistiocytosis, Hepatosplenomegaly, Hyperferritinemia, Hypertriglyceridemia, Pancytopenia.

How to cite this article: Bhuta P, Patel A, Yadav L, Patel U, Kosamia V, Muley A. A Fatal Case of Pyrexia of Unknown Origin: Hemophagocytic Lymphohistiocytosis? J Postgrad Med Edu Res 2017;51(4):188-191.

Source of support: Nil

Conflict of interest: None

\footnotetext{
${ }^{1-4}$ Resident, ${ }^{5}$ Assistant Professor, ${ }^{6}$ Professor

${ }^{1-6}$ Department of Medicine, Smt. B.K. Shah Medical Institute \& Research Centre, Vadodara, Gujarat, India

Corresponding Author: Arti Muley, Professor, Department of Medicine, Smt. B.K. Shah Medical Institute \& Research Centre Vadodara, Gujarat, India, Phone: +919879609196, e-mail: muleyarti40@gmail.com
}

\section{BACKGROUND}

Hemophagocytic lymphohistiocytosis is a potentially life-threatening hyperinflammatory syndrome caused by many inherited or secondary factors. Currently, multicenter studies are lacking, but reports from singlecenter studies have shown the incidence of $0.12 / 100,000$ per year in familial-HLH (F-HLH) and 0.36/100,000 per year in malignancy-associated HLH patients. ${ }^{1}$ In both these forms, normal $\mathrm{T}$ lymphocytes and macrophages become hyperactive, leading to alterations in clinical and hematological profiles and death in the absence of treatment. ${ }^{2}$ Although rare, an increase in HLH reports has been seen in the last decade. It was earlier thought to be a children's disease ( $<14$ years old), but now cases are also being reported in adults. ${ }^{3-5}$ It has a wide spectrum of clinical manifestations as well as considerable morbidity and mortality.

In untreated F-HLH), the median survival time reported in various studies is 2 to 6 months after diagnosis. The series collected by the International Hemophagocytic Lymphohistiocytosis Registry reported a less than $10 \%$ probability of survival for 3 years. ${ }^{6}$ In a study, "Adverse Outcomes in Primary Haemophagocytic Lymphohistocytosis," it was found that $50 \%$ of deaths from F-HLH were due to underdiagnosed invasive fungal infections. ${ }^{7}$ Secondary (acquired) HLH occurs after strong immunologic activation, such as that with systemic infection, immunodeficiency, or underlying malignancy. ${ }^{2}$ The outcomes of secondary HLH may vary. We present a case of rapidly fatal HLH in a young adult, who did not have any lymphadenopathy or neurological or cutaneous manifestations.

\section{CASE REPORT}

A 30-year-old married male presented with complaints of fever since 25 days and cough with expectoration since 15 days. Fever was high grade and intermittent with 2 to 3 spikes/day. It was associated with chills, bodyache, nausea, and vomiting. The fever used to come to baseline with medication. After 10 days, he started having whitish expectoration, 6 to 7 spoons per day, more in supine position. He also complained of headache, decreased appetite, and sleep disturbances. There was no history of rash, diarrhea, constipation, breathlessness, burning 
A Fatal Case of PUO: Hemophagocytic Lymphohistiocytosis?

Table 1: Investigation reports of the patient

\begin{tabular}{lllll}
\hline Investigations & Day of admission & 6 th day & 23rd day & 31st day \\
\hline $\mathrm{Hb}$ (gm/dl) & 9.9 & 7.3 & 4.7 & 5.3 \\
WBC (/cu.mm) & 4100 & 4000 & 1500 & 1300 \\
Differential count (/cu.mm) & $50 / 45 / 2 / 3$ & $38 / 53 / 4 / 5$ & $45 / 47 / 7 / 7$ & $69 / 25 / 3 / 3$ \\
Platelets (lakh /cu.mm) & 1.20 & 1.20 & 0.20 & $<0.29$ \\
Urea (mg/dl) & 27 & 25 & 25 & 31 \\
Creatinine (mg/dl) & 1.2 & 0.9 & 0.9 & 1.1 \\
Billirubin (mg/dl) & 1.1 & 0.9 & 0.4 & 0.8 \\
Direct & 0.8 & 0.8 & 0.2 & 0.4 \\
Indirect & 0.3 & 0.1 & 0.2 & 0.4 \\
SGOT (IU) & 115 & 119 & 114 & 86 \\
SGPT (IU) & 132 & 122 & 104 & 139 \\
\hline
\end{tabular}

Usg Abdomen - hepatosplenomegaly, oedematous Gall bladder wall but no lymph nodes; fundus examination revealed inflammatory changes in retina; UGI scopy was suggestive of fundal gastritis. Colonoscopy was normal; INR was 1.46, Peripheral smear showed lymphocytosis, Reticulocyte count was $1 \%$, IgG VCA, IgG EBNA, CMV IgG were positive. Total protein = 4.02 Albumin = 2.13 Globulin $=1.89 \mathrm{~A} / \mathrm{g}=1.12$. s. Ferritin (IFMA)- 746.6, S. LDH-2732, Lipid profile- cholesterol $-87 \mathrm{mg} / \mathrm{dl}$, triglycerides $-278 \mathrm{mg} / \mathrm{dl}$, HDL- $15 \mathrm{mg} /$ dl, LDL- $16.40 \mathrm{mg} / \mathrm{dl}$, VLDL- $55.6 \mathrm{mg} / \mathrm{dl}$, Procalcitonin- $3.79 \mathrm{ng} / \mathrm{ml}$ (normal $<0.5,2>$ severe bacterial infection); blood culture - First two were negative, third sent during third week of hospital stay showed coagulase positive staphylococcus; CT scan of thorax, abdomen \& pelvis: Moderate hepatosplenomegaly with possibility of splenic infarct. Pericholecystic thickening with oedema, Left side mild pleural effusion, possiblity of changes of hepatitis \& right renal calculus; bone marrow aspiration (fig. 1): Mildly hypocellular with decreased M:C ratio. Erythroid series showed hyperplasia with mild megaloblastic changes, lymphoid series was normal; negative findings: M.P, M.P antigen, stool OB, X-ray chest, sickling, sputum Gram \& Z.N Stain, AFB, Mantoux, PCR for M.T.B, HIV, HBsAg, HCV, HAV, HEV,WIDAL, Rheumatoid Antigen, ANA, Leptospira, VDRL, CMV IgM, ASO, ANA, IgM VCA, IgM EBNA, IgM CMV, Brucellosis

micturition, abdominal pain, joint pain, hematemesis, hemoptysis, petechiae, or malena. No aggravating factor of cough could be identified. He had a history of pulmonary tuberculosis for which he took 9 months' treatment in his childhood. He also gave history of jaundice 7 years ago. However, no past records were available. There was no history of diabetes, hypertension, bronchial asthma, or blood transfusion. He was married 2 years back and had a healthy child of 8 months. He was a vegetarian. His appetite was reduced. He did not have any history of addiction or allergy. General and systemic examinations were normal except for the presence of pallor and hepatosplenomegaly.

At the time of admission, his hemoglobin was $9.9 \mathrm{gm} /$ $\mathrm{dL}$, white blood cells $4,100 / \mathrm{cu} . \mathrm{mm}$, platelets $1.20 / \mathrm{cu} . \mathrm{mm}$, all of which decreased with progression of the disease. Lymphocytosis was noted on peripheral smear with no abnormal cells (Table 1). Other remarkable findings on investigations were hepatosplenomegaly on ultrasonography abdomen, inflammatory changes in retina on fundus examination, and elevated serum levels of ferritin, lactate dehydrogenase, and triglycerides. The bone marrow examination revealed normal hematopoesis (Fig. 1).

\section{TREATMENT}

On admission, the patient was given empirical broad-spectrum antibiotics (third-generation cephalosporins and quinolones were started initially). As the fever did not respond, $\beta$-lactams with linezolid and antibiotics with anaerobic and atypical coverage were also given. (Blood culture was negative twice during the first 2 weeks of stay.) As no response

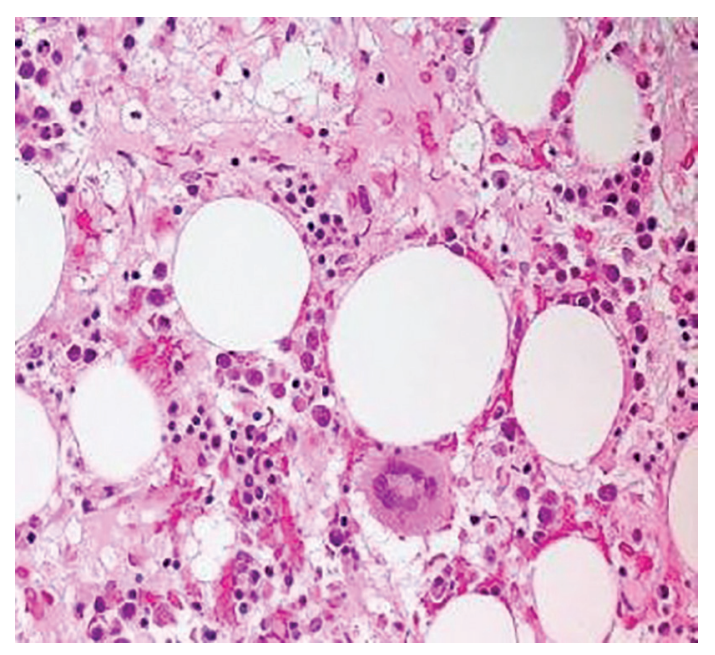

Fig. 1: Bone marrow of the patient showing no abnormal cells

was seen, he was also given empirical carbapenems, antimalarial, antitubercular, and antifungal therapy with multivitamins and other supportive treatments. However, he did not respond to any of the above treatments. As the fever still persisted, his general condition appeared to be worsening with persistence of high-grade fever, so we started methylprednisolone. The patient became afebrile the very next day of starting methylprednisolone, but fever relapsed as soon as it was stopped.

Multiple blood transfusions, i.e., packed cell volume and platelet-rich concentrate, were also given. However, the fever persisted with pancytopenia and the patient was shifted to the intensive care unit as he also developed difficulty in breathing with a few infiltrates on chest X-ray. Meanwhile, based on positive blood culture 
report received during that time, we shifted to antibiotics according to blood culture sensitivity and added to cover atypical bacteria also. The patient was discharged against medical advice due to his personal problems. He was taken to another tertiary care hospital in his city where all investigations were repeated including bone marrow with no different yield in the results. His condition continued to deteriorate and he expired about a month after his discharge from our ward.

\section{DISCUSSION}

Incidence of HLH is reported to be 1.2 cases per million persons per year. However, the figures might have slightly increased over time because of improved detection. ${ }^{2}$ First presentation of HLH could be similar to common infections like pneumonia, fever of unknown origin, malignancies, or autoimmune disorders. ${ }^{8}$ The clinical features are suggested to be due to hyperactivity of lymphocytes and macrophages leading to increased activity of cytokines like tumor necrosis factor $\alpha$, interferon- $\gamma$, interleukin (IL)-10, IL-12, and IL-18. ${ }^{9}$ Typical presenting features are prolonged fever, hepatosplenomegaly, and nonresponsiveness to antibiotics. Laboratory features commonly encountered are cytopenias, usually beginning with thrombocytopenia progressing to severe pancytopenia, elevated ferritins, elevated transaminases, hypofibrinogenemia, disseminated intravascular coagulation, hypertriglyceridemia, hypoalbuminemia, and hyponatremia ${ }^{6}$ (Table 2).

Table 2: Current diagnostic criteria $^{18}$

\begin{tabular}{|c|c|}
\hline $\begin{array}{l}\text { The diagnosis of HLH may be } \\
\text { established by }\end{array}$ & $\begin{array}{l}\text { Criteria present } \\
\text { in our patient }\end{array}$ \\
\hline $\begin{array}{l}\text { A molecular diagnosis consistent with } \mathrm{HLH} \\
\text { (for ex: Pathologic mutations of PRF1, } \\
\text { UNC13D or STX11 are identified) } \\
\text { OR }\end{array}$ & \\
\hline $\begin{array}{l}\text { Fulfilment(correct spelling) of five out of the } \\
\text { eight criteria listed below }\end{array}$ & \\
\hline Fever & * \\
\hline Splenomegaly & * \\
\hline $\begin{array}{l}\text { Cytopenias (affecting atleast two of three } \\
\text { lineages in the peripheral blood): } \\
\text { Hemoglobin }<9 \mathrm{gm} / 100 \mathrm{ml} \\
\text { Platelets }<100 \times 10^{3} / \mathrm{ml} \\
\text { Neutrophils }<1 \times 10^{3} / \mathrm{ml}\end{array}$ & * \\
\hline $\begin{array}{l}\text { Hypertriglyceridemia (fasting }>= \\
265 \mathrm{mg} / 100 \mathrm{ml}) \text { and/or hypofibrogenemia } \\
(<=150 \mathrm{mg} / 100 \mathrm{ml})\end{array}$ & * \\
\hline $\begin{array}{l}\text { Hemophagocytosis in BM, spleen or } \\
\text { lymphnodes }\end{array}$ & \\
\hline Low or absent NK cell activity & \\
\hline Ferritin $>=500 \mathrm{ng} / \mathrm{ml}$ & * \\
\hline $\begin{array}{l}\text { Soluble CD25 (i.e soluble IL-2 receptor) } \\
>2400 \mathrm{U} / \mathrm{ml} \text { (or per local reference laboratory) }\end{array}$ & \\
\hline
\end{tabular}

The HLH is a rapidly progressive and fatal disease. Patients usually do not respond to antibiotics and require aggressive therapies like etoposide, high-dose intravenous immunoglobulin G, antithymocyte globulins, cyclosporine A, and steroid to target activated macrophages, histiocytes, and T cells. ${ }^{10}$ Those who do not respond to steroids also require hematopoietic stem cell transplant (HSCT). With other treatments and HSCT, the 5-year survival probability improves from 0 to 45 to $75 \%$. ${ }^{11}$ The reason for poor survival in these patients may be delayed diagnosis due to unavailability of high-soluble CD25 levels and NK cell activity tests. ${ }^{12,13}$ The HLH secondary to Epstein-Barr virus (EBV) infection with high EBV genome copy numbers is also considered to be related to poor prognosis, ${ }^{14,15}$ which is attributed to delay in diagnosis as a result of similarity between its initial clinical presentation to that of common infective and inflammatory conditions. However, improved outcomes have been reported with the use of rituximab, etoposide, ${ }^{16}$ and HSCT. ${ }^{17}$ Use of High-dose dexamethasone, etoposide, and cyclosporine A (CSA) has also been studied together with intrathecal methotrexate (IT MTX) for patients in whom CNS-HLH did not remit after 2 weeks of dexamethasone with favourable outcome. ${ }^{18}$

Our case was a young adult, with no lymphadenopathy, rashes, skin involvement, neurologic deficits, or history of seizures. His bone marrow was normal with normal lymphoid series. However, based on presence of other five criteria, i.e., fever, splenomegaly, pancytopenia, hypertriglyceridemia, and hyperferritinemia, we diagnosed it as HLH. The case proved to be fatal even before any bone marrow abnormality became evident. This case is similar to a previous report in that although examination of bone marrow slides has the highest sensitivity for the detection of $\mathrm{HLH}$, approximately $20 \%$ of patients may not have features of HLH on initial bone marrow examination and hemophagocytic activity also may not become evident before it becomes fatal. ${ }^{6}$ Hence, suspicion for this disease entity should not be based only on bone marrow examination. It should always be considered in a patient with prolonged fever as the only hope for the patient comes from aggressive diagnosis and treatment.

\section{CONCLUSION AND CLINICAL SIGNIFICANCE}

The HLH is a rapidly progressive fatal disease entity. It may present in adults also and bone marrow abnormalities may not appear even late in the course of the disease. Presence of other nonspecific features together might give a clue regarding the diagnosis. A high degree of suspicion and aggressive approach is needed to diagnose HLH. There is 
a need for developing a better tool for early diagnosis and also delineating a specific treatment plan for improving prognosis of this otherwise fatal disease.

\section{REFERENCES}

1. Machaczka M, Vaktnas J, Klimkowska M, Hagglund H. Malignancy-associated hemophagocytic lymphohistiocytosis in adults: a retrospective population-based analysis from a single center. Leuk Lymphoma 2011 Apr;52(4):613-619.

2. Malloy CA, Polinski C, Alkan S, Manera R, Challapalli M. Hemophagocytic lymphohistiocytosis presenting with nonimmune hydrops fetalis. J Perinatol 2004 Jul;24(7):458-460.

3. Janka GE, Lehmberg K. Hemophagocytic syndromes-an update. Blood Rev 2014 Jul;28(4):135-142.

4. Nagafuji K, Nonami A, Kumano T, Kikushige Y, Yoshimoto G, Takenaka K, Shimoda K, Ohga S, Yasukawa M, Horiuchi H, et al. Perforin gene mutations in adult-onset hemophagocytic lymphohistiocytosis. Haematologica 2007 Mar;92:978-981.

5. Zhang K, Jordan MB, Marsh RA, Johnson JA, Kissell D, Meller J, Villanueva J, Risma KA, Wei Q, Klein PS, et al. Hypomorphic mutations in PRF1, MUNC13-4, and STXBP2 are associated with adult-onset familial HLH. Blood 2011 Nov;118(22): 5794-5798.

6. Aricò M, Janka G, Fischer A, Henter JI, Blanche S, Elinder G, Martinetti M, Rusca MP. Hemophagocytic lymphohistiocytosis. Report of 122 children from the International Registry. FHL Study Group of the Histiocyte Society. Leukemia 1996 Feb;10(2):197-203.

7. Sung L, King SM, Carcao M, Trebo M, Weitzman SS. Adverse outcomes in primary hemophagocytic lymphohistiocytosis. J Pediatr Hematol Oncol 2002 Oct;24(7):550-554.

8. Janka GE. Hemophagocytic syndromes. Blood Rev 2007 Sep;21(5):245-253.

9. Larroche C, Mouthon L. Pathogenesis of hemophagocytic syndrome (HPS). Autoimmun Rev 2004 Feb;3(2):69-75.

10. Filipovich AH. Hemophagocytic lymphohistiocytosis (HLH) and related disorders. Hematology Am Soc Hematol Educ Program 2009 Dec:127-131.
11. Trottestam H, Horne A, Arico M, Egeler RM, Filipovich AH, Gadner H, Imashuku S, Ladisch S, Webb D, Janka G, et al. Chemoimmunotherapy for hemophagocytic lymphohistiocytosis: long-term results of the HLH-94 treatment protocol. Blood 2011 Oct;118(17):4577-4584.

12. Switala JR, Hendricks M, Davidson A. Serum ferritin is a cost-effective laboratory marker for hemophagocytic lymphohistiocytosis in the developing world. J Pediatr Hematol Oncol 2012 Apr;34(3):e89-e92.

13. Lehmberg K, McClain KL, Janka GE, Allen CE. Determination of an appropriate cut-off value for ferritin in the diagnosis of hemophagocytic lymphohistiocytosis. Pediatr Blood Cancer 2014 Nov;61(11):2101-2103.

14. Imashuku S, Teramura $T$, Tauchi $H$, Ishida $Y$, Otoh $Y$, Sawada $M$, Tanaka H, Watanabe A, Tabata Y, Morimoto A, et al. Longitudinal follow-up of patients with Epstein-Barr virus-associated hemophagocytic lymphohistiocytosis. Haematologica 2004 Feb;89(2):183-188.

15. Kunitomi A, Kimura H, Ito Y, Naitoh K, Noda N, Iida H, Sao H. Unrelated bone marrow transplantation induced longterm remission in a patient with life-threatening Epstein-Barr virus-associated hemophagocytic lymphohistiocytosis. J Clin Exp Hematop 2011;51(1):57-61.

16. Shabbir M, Lucas J, Lazarchick J, Shirai K. Secondary hemophagocytic syndrome in adults: a case series of 18 patients in a single institution and a review of literature. Hematol Oncol 2011 Jun;29(2):100-106.

17. Ohga S, Kudo K, Ishii E, Honjo S, Morimoto A, Osugi $Y$, Sawada A, Inoue M, Tabuchi K, Suzuki N, et al. Hematopoietic stem cell transplantation for familial hemophagocytic lymphohistiocytosis and Epstein-Barr virus-associated hemophagocytic lymphohistiocytosis in Japan. Pediatr Blood Cancer 2010 Feb;54(2):299-306.

18. Henter JI, Horne A, Arico’ M, Egeler RM, Filipovich AH, Imashuku S, Ladisch S, McClain K, Webb D, Winiarski J, et al. HLH-2004: diagnostic and therapeutic guidelines for hemophagocytic lymphohistiocytosis. Pediatr Blood Cancer 2007 Feb;48(2):124-131. 